\title{
Adolescent Brain Development and the Risk for Alcohol and Other Drug Problems
}

\author{
Sunita Bava $\cdot$ Susan F. Tapert
}

Received: 10 August 2010 / Accepted: 5 October 2010 /Published online: 19 October 2010

(C) The Author(s) 2010. This article is published with open access at Springerlink.com

\begin{abstract}
Dynamic changes in neurochemistry, fiber architecture, and tissue composition occur in the adolescent brain. The course of these maturational processes is being charted with greater specificity, owing to advances in neuroimaging and indicate grey matter volume reductions and protracted development of white matter in regions known to support complex cognition and behavior. Though fronto-subcortical circuitry development is notable during adolescence, asynchronous maturation of prefrontal and limbic systems may render youth more vulnerable to risky behaviors such as substance use. Indeed, binge-pattern alcohol consumption and comorbid marijuana use are common among adolescents, and are associated with neural consequences. This review summarizes the unique characteristics of adolescent brain development, particularly aspects that predispose individuals to reward seeking and risky choices during this phase of life, and discusses the influence of substance use on neuromaturation. Together, findings in this arena underscore the importance of refined research and programming efforts in adolescent health and interventional needs.
\end{abstract}

Support for this review was made possible by grants from the National Institute on Alcohol Abuse and Alcoholism (R01 AA13419) and the National Institute on Drug Abuse (R01 DA021182, P20 DA024194, P20 DA027834, and F32 DA024476).

S. Bava $\cdot$ S. F. Tapert $(\bowtie)$

VA San Diego Healthcare System,

3350 La Jolla Village Drive (151B),

San Diego, CA 92126, USA

e-mail: stapert@ucsd.edu

S. Bava $\cdot$ S. F. Tapert

Department of Psychiatry, University of California, San Diego,

9500 Gilman Drive (0603),

La Jolla, CA 92093-0603, USA
Keywords Adolescence $\cdot$ Substance use $\cdot$ Alcohol . Marijuana $\cdot$ Risk taking $\cdot$ Neuromaturation

\section{Introduction}

Adolescence is a time of subtle, yet dynamic brain changes that occur in the context of major physiological, psychological, and social transitions. This juncture marks a gradual shift from guided to independent functioning that is analogized in the protracted development of brain structure. Growth of the prefrontal cortex, limbic system structures, and white matter association fibers during this period are linked with more sophisticated cognitive functions and emotional processing, useful for navigating an increasingly complex psychosocial environment. Despite these developmental advances, increased tendencies toward risk-taking and heightened vulnerability to psychopathology are well known within the adolescent milieu. Owing in large part to progress and innovation in neuroimaging techniques, appreciable levels of new information on adolescent neurodevelopment are breaking ground. The potential of these methods to identify biomarkers for substance problems and targets for addiction treatment in youth are of significant value when considering the rise in adolescent alcohol and drug use and decline in perceived risk of substance exposure (Spear 2010).

What are the unique characteristics of the adolescent brain? What neural and behavioral profiles render youth at heightened risk for substance use problems, and are neurocognitive consequences to early substance use observable? Recent efforts have explored these questions and brought us to a fuller understanding of adolescent health and interventional needs. This paper will review neurodevelopmental processes during adolescence, discuss the 
influence of substance use on neuromaturation as well as probable mechanisms by which these substances influence neural development, and briefly summarize factors that may enhance risk-taking tendencies. Finally, we will conclude with suggestions for future research directions.

\section{Adolescent Brain Development}

Overall brain size changes little beyond early school age (Pfefferbaum et al. 1994), though the adolescent brain continues to undergo considerable maturation (BarneaGoraly et al. 2005; Paus et al. 1999; Sowell et al. 1999). Changes in cortical volume occur alongside axonal growth and refinement of cortical connections (Huttenlocher and Dabholkar 1997; Yakovlev and Lecours 1967). Maturing neural circuitry, particularly in the prefrontal cortex, limbic system, and white matter association and projection fibers is linked with advancements in cognition and behavior, but also renders the adolescent brain vulnerable to unhealthy environmental influences.

\section{Grey Matter}

The developmental trajectory of grey matter follows an inverted parabolic curve, with cortical volume peaking, on average, around ages 12-14, followed by a decline in volume and thickness over adolescence (Giedd et al. 1999; Gogtay et al. 2004; Sowell et al. 2003). Widespread supratentorial diminutions are evident, but show temporal variance across regions (Wilke et al. 2007). Declines begin in the striatum and sensorimotor cortices (Jernigan and Tallal 1990; Jernigan et al. 1991; Sowell et al. 1999), progress rostrally to the frontal poles, then end with the dorsolateral prefrontal cortex (Gogtay et al. 2004; Sowell et al. 2002b), which is also late to myelinate (Paus et al. 1999). Longitudinal charting of brain volumetry (Giorgio et al. 2010) from 13-22 years of age reveals specific declines in medial parietal cortex, posterior temporal and middle frontal gyri, and the cerebellum in the right hemisphere, coinciding with previous studies showing these regions to develop late into adolescence (Giedd 2004; Gogtay et al. 2004; Sowell et al. 2002a, b). Examination of developmental changes in cortical thickness from 8-30 years of age indicates a similar pattern of nonlinear declines, with marked thinning during adolescence. Attenuations are most notable in the parietal lobe, and followed in effect size by medial and superior frontal regions, the cingulum, and occipital lobe (Tamnes et al. 2009).

The mechanisms underlying cortical volume and thickness decline are suggested to involve selective synaptic pruning of superfluous neuronal connections, reduction in glial cells, decrease in neuropil and intra-cortical myelina- tion (Huttenlocher and Dabholkar 1997; Paus et al. 2008; Shaw et al. 2008; Tamnes et al. 2009). Regional variations in grey matter maturation may coincide with different patterns of cortical development, with allocortex, including the piriform area, showing primarily linear growth patterns, compared to transition cortex (orbitofrontal, insular, cingulate, entorhinal, and perirhinal regions) demonstrating a combination of linear and quadratic trajectories, and isocortex (medial and lateral prefrontal, precentral motor, somatosensory, lateral temporal, and lateral occipital regions) demonstrating cubic growth curves (Shaw et al. 2008). Though the functional implications of these developmental trajectories are unclear, isocortical regions undergo more protracted development and support complex behavioral functions. Their growth curves may reflect critical periods for development of cognitive skills as well as windows of vulnerability for neurotoxic exposure or other developmental perturbations.

\section{White Matter}

In contrast to grey matter reductions, white matter across the adolescent years shows growth and enhancement of pathways (Giedd 2008; Yakovlev and Lecours 1967). This is reflected in white matter volume increase, particularly in fronto-parietal regions (Benes 1989; Huttenlocher 1990; Nagel et al. 2006; Yakovlev and Lecours 1967). Diffusion tensor imaging (DTI), a neuroimaging technique that has gained widespread use over the past decade, relies on the intrinsic diffusion properties of water molecules and has afforded a view into the more subtle microstructural changes that occur in white matter architecture. Two common scalar variables derived from DTI are fractional anisotropy (FA), which describes the directional variance of diffusional motion, and mean diffusivity (MD), an indicator of the overall magnitude of diffusional motion. These measures index relationships between signal intensity changes and underlying tissue structure, and provide descriptions of white matter quality and architecture (Conturo et al. 1999; Pierpaoli and Basser 1996; Shimony et al. 1999). High FA reflects greater fiber organization and coherence, myelination and/or other structural components of the axon, and low MD values suggest greater white matter density (Roberts and Schwartz 2007). Studies of typically developing adolescents show increases in FA and decreases in MD. These trends continue through early adulthood in a nearly linear manner (Barnea-Goraly et al. 2005; Bonekamp et al. 2007; Mukherjee et al. 2001; Schmithorst et al. 2002), though recent data suggest an exponential pattern of anisotropic increase that may plateau during the late-teens to early twenties (Lebel et al. 2008).

Areas with the most prominent FA change during adolescence are the superior longitudinal fasciculus, supe- 
rior corona radiata, thalamic radiations, and posterior limb of the internal capsule (see Fig. 1) (Bava et al. 2010b). Other projection and association pathways including the corticospinal tract, arcuate fasciculus, cingulum, corpus callosum, superior and mid-temporal white matter, and inferior parietal white matter show anisotropic increases as well (Ashtari et al. 2007; Bonekamp et al. 2007; Giorgio et al. 2010; Giorgio et al. 2008; Tamnes et al. 2009). Changes in subcortical and deep grey matter fibers are more pronounced, with less change in compact white matter tracts comprising highly parallel fibers such as the internal capsule and corpus callosum (Bava et al. 2010b; Lebel et al. 2008). Fiber tracts constituting the fronto-temporal pathways appear to mature relatively later (Schneiderman et al. 2007; Tamnes et al. 2009), though comparison of growth rates among tracts comes largely from cross-sectional data that present developmental trends.

The neurobiological mechanisms contributing to FA increases and MD decreases during adolescence are not entirely understood, but examination of underlying diffusion dynamics point to some probable processes. For example, decreases in radial diffusivity (RD), diffusion that occurs perpendicular to white matter pathways, suggests increased myelination, axonal density, and fiber compactness (Giorgio et al. 2008; Snook et al. 2005), but have not been uniformly observed to occur during adolescence. Similarly, changes in axial diffusivity (AD), diffusion parallel to the fibers' principle axis, show discrepant trends, with some studies documenting decreases (Eluvathingal et al. 2007; Lebel et al. 2008; Suzuki et al. 2003), and others increases in this index (Ashtari et al. 2007; Giorgio et al. 2010). Decreases in AD may be attributable to developing axon collaterals, whereas increases may reflect growth in axon diameter, processes which are both likely to occur during adolescence. Technical and demographic differences such as imaging parameters, inter-scan intervals, age range, and gender ratios may account for divergent findings.
Both grey matter volume decreases and FA increases in frontoparietal regions occur well into adolescence, suggesting a close spatiotemporal relationship (Gogtay et al. 2004; Lebel et al. 2008). Changes in tissue morphometry are attributable to synaptic proliferation and pruning (Huttenlocher 1979) as well as myelination. Diminutions in gray matter density and concomitant brain growth in dorsal parietal and frontal regions suggest an interplay between regressive and progressive changes (Sowell et al. 2001), and the coupling of these neurobiological processes is associated with increasingly economical neural activity (Huttenlocher and Dabholkar 1997).

\section{Sexual Dimorphisms in Brain Structure}

The increasing divergences in male and female physiology during adolescence are observed in sex-based differentiation of brain structure. Male children and adolescents show larger overall brain volumes (Caviness et al. 1996; Reiss et al. 1996), and proportionally larger amygdala and globus pallidus sizes, while females demonstrate larger caudate nuclei and cingulate gyrus volumes (Caviness et al. 1996; Giedd et al. 1997; Wilke et al. 2007). Although cortical and subcortical grey matter volumes typically peak 1-2 years earlier in females than males (Lenroot and Giedd 2006), male children and adolescents show more prominent grey matter reductions and white matter volume increases with age than do females (Blanton et al. 2004; De Bellis et al. 2001).

The marked increase in white matter that occurs during adolescence is most prominent in the frontal lobe for both genders (Giedd et al. 1999), though male children and adolescents have significantly larger volumes of white matter surrounding the lateral ventricles and caudate nuclei than females (Hua et al. 2009). Adolescent males also demonstrate a significantly higher rate of change in white matter volume (De Bellis et al. 2001; Lenroot et al. 2007;
Fig. 1 Clusters of significant change in the superior longitudinal fasciculus over time in adolescents age 17.5 to 19 ( $\geq 153 \mu \mathrm{l}, p<.01 ; N=22$ ) (Bava et al. 2010a, b). Results are superimposed on a fiber skeleton (blue) and overlaid on a standardized template. Images are in radiological convention
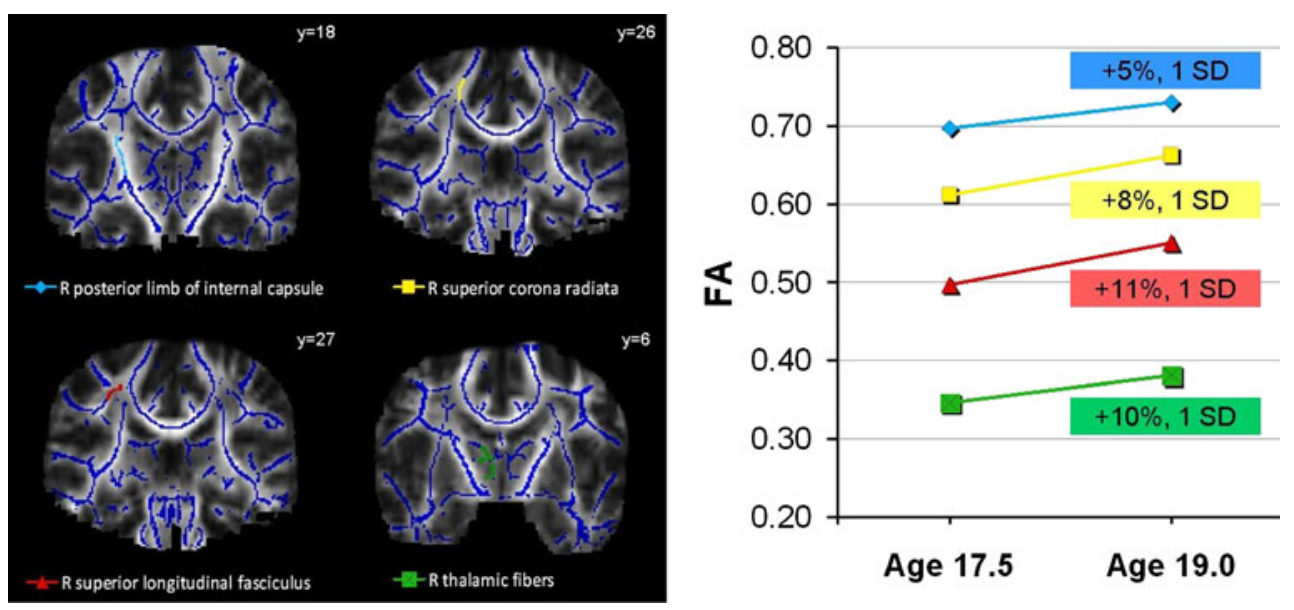

Age 17.5 Age 19.0 
Perrin et al. 2008) particularly in the occipital lobe (Perrin et al. 2009). Despite steeper white matter volume changes in males, maturation of white matter microstructure may occur earlier in female than male adolescents (Asato et al. 2010).

Findings on white matter microstructure provide further evidence of different neuromaturational trajectories for boys and girls. In a whole-brain voxelwise DTI study of 106 children and adolescents 5-18 years of age, males had higher FA in bilateral frontal white matter areas, right arcuate fasciculus, and left parietal and occipito-parietal regions, while females showed higher FA in the splenium of the corpus callosum (Schmithorst et al. 2008). Females displayed age-related increases in FA in all regions, whereas males did not. Other findings suggest higher FA in the genu in adolescent males compared to females (Silveri et al. 2006), while fiber tract analysis of 31 children and adolescents documents no sex-related FA differences (Eluvathingal et al. 2007). It is possible that power differences in voxelwise versus tractography methods and in sample size contribute to discrepant findings.

Different mechanisms of white matter growth, specifically, an increase in axonal diameter in males and a growth in myelin content in females, are implicated from magnetization-transfer ratio analysis (Perrin et al. 2009). Indeed, higher levels of lutenizing hormone is associated with greater white matter content (Peper et al. 2008), and increasing testosterone levels may influence axonal diameter in males (Perrin et al. 2008). Together, these findings suggest a role for sex hormones in developmental trajectories of cortical and white matter maturation.

\section{Neurotransmitters}

Some neurotransmitter systems appear to show refinement during the teenage years. Brain regions with input from the neurotransmitter dopamine that comprise the reward system (i.e., prefrontal cortex, striatum, and nucleus accumbens) undergo pronounced developmental changes during adolescence (Spear 2009). In particular, the density of dopaminergic connections to the prefrontal cortex increases in this phase of life (Lambe et al. 2000; Rosenberg and Lewis 1994; Tunbridge et al. 2007). Activity of the dopamine degrading enzyme catechol-O-methyltransferase (COMT) appears to increase in mid-adulthood (after age 30) based on post mortem studies (Tunbridge et al. 2007), but does not differ between infants, adolescents, and young adults. This post-adolescent maturation may facilitate improved dopaminergic transmission to and within the prefrontal cortex. Dopamine synthesis and turnover in portions of the prefrontal cortex that project to subcortical regions (e.g., striatum) increase from adolescence to adulthood (Andersen et al. 1997; Teicher et al. 1993), and this dopamine balance shift between prefrontal and subcortical structures may be due to pruning in the neocortex (Bourgeois et al. 1994; Woo et al. 1997).

In a study from Sweden, binding potential of the dopamine D1 receptor (the most abundant of the DA receptor subtypes) was evaluated in individuals spanning ages 10-30 using positron emission tomography. Binding potential declined non-linearly in all regions, most prominently in cortical regions including the dorsolateral prefrontal cortex during adolescence, with reductions of $26 \%$ from adolescence to young adulthood in frontal, anterior cingulate, and occipital cortex over one decade. A slower to flat decline in binding potential was seen for orbitofrontal and posterior cingulate and striatal regions (Jucaite et al. 2010). Expression of the dopamine D2 receptors in the prefrontal cortex peak in infancy then by adolescence reach adult levels (Weickert et al. 2007). In contrast, prefrontal levels of the dopamine receptor D4 show little change with age (Weickert et al. 2007). Overall, the development of dopaminergic transmission varies across particular receptor types, with some showing marked changes well into the third decade of life, past the stage typically considered adolescence.

The inhibitory GABAergic system also shows development during adolescence. In rats, fibers from the basolateral amygdala continue to form connections with GABAergic interneurons in the prefrontal cortex throughout periadolescence (Cunningham et al. 2002, 2008). In non-human primates, GABAergic inputs to pyramidal cells undergo changes during the perinatal period and adolescence (Akil and Lewis 1992; Cruz et al. 2003) in concert with continued maturation of behaviors mediated by the prefrontal cortex (Cruz et al. 2009). The timing of improved executive functioning and working memory performance appears to correspond with maturing GABAergic inhibitory circuits containing the protein parvalbumin (Behrens and Sejnowski 2009; Rao et al. 2000; Uhlhaas et al. 2009). In humans, the input to GABAergic interneurons in the prefrontal cortex appears to decrease strongly from adolescence to adulthood (Lewis 1997; Spear 2000).

Neurotransmission is influenced by activity in receptors for adrenal and gonadal hormones. Puberty-related hormonal development begins with changes in excitatory and inhibitory inputs to gonadotropin-releasing hormone neurons in the pituitary gland. This activity has clear influences on aggression and sexual behavior, but a less clear role concerning impulsivity and cognition (Paus et al. 2008).

The neurotransmitter changes occurring during adolescence are in synchrony with the anatomical changes seen in the prefrontal cortex and other brain regions during this stage, as well as maturation of cognition and behavior and the emerging increased risk for psychopathology (Paus et al. 2008). Changes in dopamine and reward circuitry are 
critical to assigning value and reinforcing behaviors, such as social interaction, food consumption, romantic behaviors, novelty seeking, and alcohol and other drug intake (Spear 2009), while ongoing refinement of inhibitory neurotransmission has broad implications for information processing and modulation of impulses.

\section{Cognitive and Social Development}

Neuromaturation in the form of brain volume, structure, and neurochemistry changes during adolescence occurs along with numerous behavioral alterations. Among these, the acquisition and demonstration of advanced cognitive skills is particularly notable. Higher-order cognitive functions such as working memory, planning, problem solving, and inhibitory control are developing during adolescence (Anderson et al. 2001; Conklin et al. 2007) and historically linked to maturation of the frontal lobes (Rubia et al. 2003; Sowell et al. 1999). The study of brain structure-function relationships has considerably burgeoned with the use of fiber tractography and fMRI, providing an appreciation for more distributed neural circuitry including frontosubcortical networks as the seat of complex cognitive and executive skills (Royall et al. 2002). The correspondence between white matter development during adolescence and neurocognitive performance has been demonstrated in a number of recent studies. Intellectual functioning in youth is associated with the development of white matter circuitry in bilateral frontal, occipito-parietal, and occipito-temporoparietal regions (Schmithorst et al. 2005). The reading skills of children and adolescents improve with white matter changes in the internal capsule, corona radiata, and temporo-parietal regions (Beaulieu et al. 2005; Nagy et al. 2004; Niogi and McCandliss 2006; Qiu et al. 2008), and greater left lateralization of the arcuate fasciculus fibers is associated with improved phonological processing and receptive vocabulary (Lebel and Beaulieu 2009). Better visuospatial construction and psychomotor performance are associated with high corpus callosum FA (Fryer et al. 2008). Visuospatial working memory capacity is linked to a fronto-intraparietal network (Olesen et al. 2003), whereas delayed visual memory is linked to temporal and occipital FA (Mabbott et al. 2009). Verbal memory proficiency is related to decreased MD and decreased RD in left uncinate fasciculus and with parietal and cerebellar white matter integrity (Mabbott et al. 2009).

As these studies are based on cross-sectional data, we examined whether the extent of white matter maturation during late adolescence would be linked to performance on measures of working memory, executive functioning, and learning and recall. Greater extent of FA increase and RD decrease in the right posterior limb of the internal capsule over time correlated with better complex attention and phonemic fluency in adolescents, and greater increase in MD and AD in the right inferior fronto-occipital fasciculus was associated with improved visuoconstruction ability and learning and recall (Bava et al. 2010a).

\section{Socio-Emotional Processing}

The social environment reaches heightened salience in adolescence when self-monitoring, sensitivity to evaluation, and awareness of others' perspectives become increasingly apparent (Choudhury et al. 2006). Brain structures subserving socio-emotional processing continue to mature in this age group with demonstrable effects in blood-oxygenationlevel-dependent (BOLD) response. Amygdala, orbitofrontal cortex, and anterior cingulate cortex activation to facial affect processing is prominent in adolescence relative to adulthood (Monk et al. 2003; Yang et al. 2003) with shifts toward more dorsolateral prefrontal activation with age (Yurgelun-Todd and Killgore 2006). Differences in activation patterns, with girls showing bilateral and boys only right prefrontal response, may underlie sex-related nuances in behavioral response to affect and emotion. Nonetheless, adolescents as a group show elevated activity in bottom-up emotion processing centers (Hare et al. 2008), suggesting that they are more likely to be influenced by emotional context than adults. As a result, poor decisions are often made in states of emotional reactivity. Although increased frontoamygdala activity during emotional processing habituates with repeated exposure, individuals with higher selfrated trait anxiety show less adaptation over time.

\section{Reward Sensitivity}

Adolescents' proclivity toward risk-taking behavior and susceptibility to poor decision-making may be related to unique neural characteristics that increase their sensitivity to rewarding outcomes. Two primary theories of reward processing in adolescence have received support, each purporting different functional trends in the striatum. One posits that hypoactivation of the striatal system leads adolescents to engage in reward seeking as a compensatory response. The other suggests that the striatum behaves in a contrasting manner; that its hyperactivity leads to greater reward-seeking behavior. Recent fMRI evidence lends support to the latter hypothesis and is reviewed in detail elsewhere (Galvan 2010). Briefly, greater ventral striatal activation has been shown in adolescents compared to children and adults in anticipation of reward (Geier et al. 2010; Galvan et al. 2006) and during reward receipt (Van Leijenhorst et al. 2010). During reward processing, BOLD signal showed attenuations in the ventral striatum when adolescents were required to assess an incentive cue, but showed elevations during reward anticipation (Geier et al. 
2010), suggesting that adolescents may have limited capacity to assess potential reward outcomes and have exaggerated reactivity when anticipating reward compared with adults. Underlying the hyperactivation of the striatum is an increase in ventral striatal dopamine release during rewarding events (Aarts et al. 2010; Koepp et al. 1998). Greater dopamine release may lead adolescents to seek additional rewards, resulting in a reinforcing cycle of reward-seeking behavior.

Pubertal maturation is associated with increases in sensation seeking (Galvan et al. 2007) and may play a role in reward sensitivity. Forbes et al. (2010) found less striatal and more medial prefrontal cortex activity in response to reward outcome (win, loss, or no-change) in adolescents with more advanced pubertal maturation compared to similar-aged adolescents with less advanced pubertal maturation. Further, the putative role of the medial prefrontal cortex in self-processing and social cognition suggests that maturing adolescents may consider the social context and peer influences when responding to reward (Forbes et al. 2010).

Affective status may interact with neural response to reward, as low striatal and high prefrontal activity were linked to depressive symptoms. Indeed, adolescents show an increase in risky behavior when the situation evokes affective processing. Hormone levels may additionally influence reward sensitivity. Higher testosterone levels were associated with reduced reward outcome-related striatal activity for both males and females, implicating a unique contribution of this hormone to reward processing. Due to their neural profiles, adolescents may show a greater propensity for high stakes rewards that incline them toward risk-taking and sensation seeking (Forbes et al. 2010; Martin et al. 2004).

\section{Substance Use and Related Problems in Adolescence}

Predilection for risk-taking and sensation seeking during adolescence is associated with increased substance use and the potential for long-term health problems. Proclivity to use is associated with a host of factors from genetic predispositions to economic influences, but particularly concerning is the evidence for neural consequences.

\section{Use Rates and Risks Associated with Early Onset}

Alcohol is by far the most widely used intoxicant among adolescents in the U.S., and rates of use increase dramatically during the teenage years (Johnston et al. 2009). By 8 th grade, $37 \%$ of students have tried alcohol, increasing to $72 \%$ by 12 th grade (Johnston et al. 2009). Past-month rates of getting drunk increase from $5 \%$ to $27 \%$, and having consumed 5 drinks in a row in the past 2 weeks expands from $8 \%$ to $25 \%$ from 8 th to 12 th graders. Nicotine is fairly widely used, with $6 \%$ of 8 th graders reporting any use in the past month, compared to $20 \%$ of 12 th graders. Marijuana is the second most used intoxicant, with $16 \%$ of 8 th graders and $42 \%$ of 12 th graders reporting use at least once in their lifetime (SAMSHA 2009), and 21\% of high school seniors endorse past month use. Other drug use is not as widespread yet still concerning, with past month use among 12th graders of amphetamines and misused narcotic pain pills at 3\% and 4\%, respectively (Johnston et al. 2009). Approximately $8 \%$ of those ages $12-17$ meet criteria for substance abuse or dependence in the past year, but this peaks between ages 18-25, when 21\% meet diagnostic criteria for a substance use disorder (SAMSHA 2009).

Those with early substance use onset are more likely to continue use into adulthood; individuals who first used alcohol at age 14 or younger have a $>5$ time increased risk of lifetime alcohol use disorder as compared to those who first used alcohol after the U.S. legal limit of the $21^{\text {st }}$ birthday (SAMSHA 2009). Adolescent alcohol and marijuana use has been linked to harmful effects on physiological, social, and psychological functioning (Macleod et al. 2004; Tucker et al. 2006a, b). This includes increased delinquency (Nation and Heflinger 2006; Shoal et al. 2007), aggressivity, risky sexual behaviors, hazardous driving, and comorbid substance use (Neal and Fromme 2007).

\section{Neural Consequences of Adolescent Substance Use}

Given the extent of brain maturation occurring during this phase in life, adolescents who use substances appear to be vulnerable to alterations in brain functioning, cognition and behavior. Indication that alcohol and marijuana use may detrimentally influence the developing brain comes from studies showing diminutions in neurocognitive functioning, especially attention, visuospatial functioning, and learning and retrieval of verbal and nonverbal information (Brown et al. 2000; Medina et al. 2007b; Tapert and Brown 1999, 2000; Tapert et al. 2002); morphological changes (Medina et al. 2008; Nagel et al. 2005); anisotropic differences in white matter (De Bellis et al. 2008); and a more distributed functional network and recruitment of alternate brain regions (see Table 1) (Jacobsen et al. 2007; Schweinsburg et al. 2008; Schweinsburg et al. 2005a; Tapert et al. 2001a, 2004, 2007).

Heavy alcohol use is associated with a wide range of neural consequences in adults (Estruch et al. 1997; Nicolas et al. 2000; Pfefferbaum et al. 2006a, b; Pfefferbaum and Sullivan 2005) and similar sequelae are implicated in adolescent users. Hippocampal (De Bellis et al. 2000; Nagel et al. 2005) and prefrontal white matter volumes appear smaller in heavy alcohol using adolescents (De 
Table 1 Brain correlates of heavy alcohol and marijuana use in adolescence

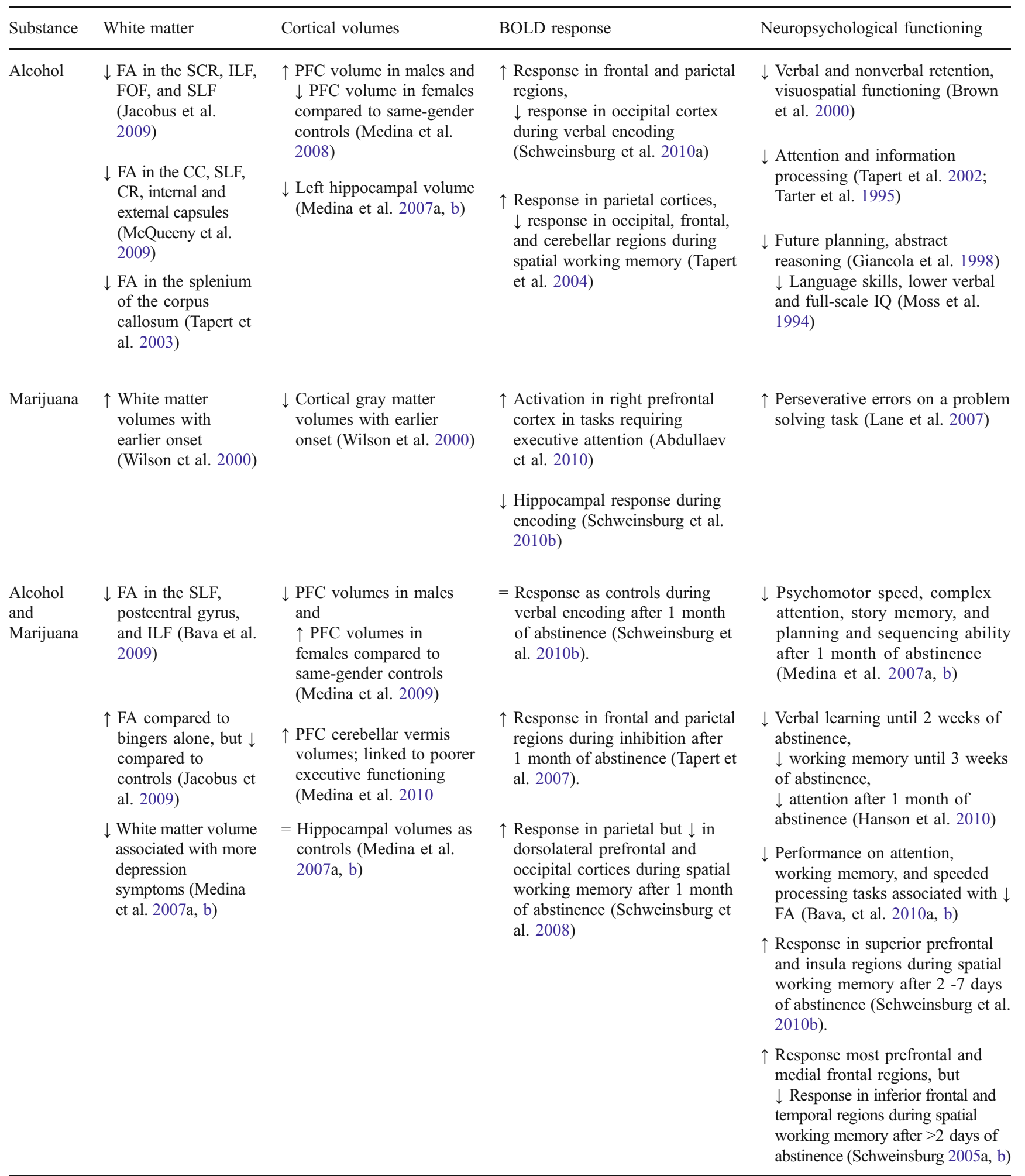

$S C R$ superior corona radiata; $I L F$ inferior longitudinal fasciculus; $F O F$ fronto-occipital fasciculus; $C C$ corpus callosum; $S L F$ superior longitudinal fasciculus; $C R$ corona radiata; $F A$ fractional anisotropy; $P F C$ prefrontal cortex; $I Q$ intelligence quotient 
Bellis et al. 2005; Medina et al. 2008). Alterations in anisotropy in the genu and isthmus of the corpus callosum in alcohol-using teens (De Bellis et al. 2008) and in frontal, cerebellar, temporal, and parietal regions in adolescent binge-drinkers (McQueeny et al. 2009) lends further support to atypical developmental trajectories. White matter quality appears to relate to drinking in a dose dependent manner, where higher blood alcohol concentrations are associated with poorer tissue integrity in the corpus callosum, internal and external capsules, and superior corona radiata (see Fig. 2) (McQueeny et al. 2009). Functional consequences of adolescent heavy drinking are seen in attenuated frontal cortex response during spatial working memory (Tapert et al. 2004), and deficits on neuropsychological measures of attention (Tapert and Brown 1999), information retrieval (Brown et al. 2000), and visuospatial functioning (Tapert et al. 2002), with some studies showing sustained effects into adulthood (Brown et al. 2008). Drinking so much that hangover or withdrawal symptoms are experienced is associated with decreased performance over time (Tapert et al. 2002).

Overall, these studies indicate that heavy drinking during adolescence may be associated with decrements in cognitive performance and brain health. However, longitudinal studies are critical to determine if substance use causes these abnormalities, or if these features predated the onset of regular substance use. One such study prospectively examined the influence of alcohol on neuropsychological functioning prior to initiation of drinking. For girls who transitioned into moderate or heavy drinking, more drinking days in the past year predicted a greater reduction in visuospatial task performance from baseline to 3-year follow-up. For boys, a tendency was seen for more past year hangover symptoms to predict poorer sustained attention (Squeglia et al. 2009).
Gender differences are seen in prefrontal cortex volumes of adolescents with alcohol use disorders, where females show smaller, and males, larger volumes than controls. In addition, limited frontal response to a spatial working memory task and reduced grey matter volume in females with alcohol use disorders compared to males suggest that females may be more vulnerable to the impairing effects of alcohol (Caldwell et al. 2005; Schweinsburg et al. 2003).

Marijuana use is also associated with atypical neural profiles. Adolescent marijuana users show a less efficient pattern of activation compared to non-users on working memory (Schweinsburg et al. 2008, 2010b), verbal learning (Schweinsburg et al. 2010a), and cognitive control (Tapert et al. 2007) tasks using fMRI. Brain response patterns in marijuana-using teens consistently indicate increased utilization of alternate brain networks (Jacobsen et al. 2007; Schweinsburg et al. 2005b; Tapert et al. 2007). In addition, users have demonstrated larger cerebellar volumes than non-users (Medina et al. 2010), and female marijuana users showed larger prefrontal cortex volumes than same-gender non-users (Medina et al. 2009), suggesting the possibility of attenuated synaptic pruning. White matter integrity is typically poorer in users than non-users, particularly in fronto-parietal circuitry and pathways connecting the frontal and temporal lobes (Bava et al. 2009). The functional implications of these differences appear disadvantageous, as marijuana-using teens show an increased susceptibility to depressive symptoms (Medina et al. 2007b) and poorer performance than non-users on neuropsychological tests of psychomotor speed, complex attention, verbal memory, planning, and sequencing ability, even after a month of sustained abstinence (Medina et al. 2007a).

The pharmacodynamics of alcohol and marijuana are the subject of study in several empirical works examining their
Fig. 2 Adolescents with histories of binge drinking show lower fractional anisotropy (FA) in the left and right superior corona radiata as compared to those with no history of binge drinking. Further, FA values here were linearly linked to blood alcohol concentrations reached in the previous 3 months, with more intense drinking linked to more abnormal white matter coherence in this dorsal frontal tract (McQueeny et al. 2009)

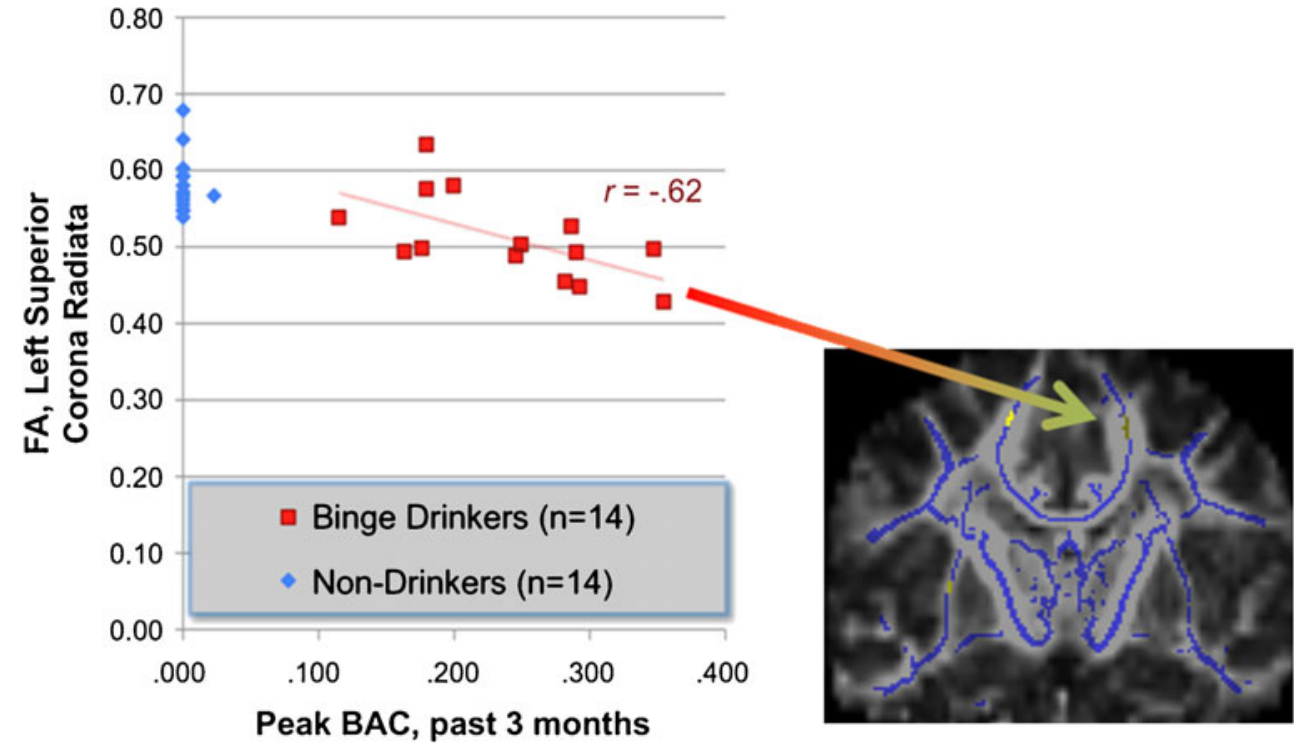


physiological and behavioral effects. Chronic alcohol exposure is associated with cortical and white matter volume loss secondary to decreases in choline and $\mathrm{N}$ acetyl aspartate, reduced GABAa receptor efficacy, and impaired neurogenesis (Crews et al. 2005; Meyerhoff et al. 2004). Similarly, the principal active component of marijuana, delta9-tetrahydrocannabinol (delta9-THC), produces complex alterations in cognition and behavior that involve several neuronal substrates (Fant et al. 1998; Johns 2001; Solowij et al. 2002). Brain regions with high densities of CB-1 receptors, and thus susceptible to the effects of THC, include the frontal regions, hippocampus, basal ganglia, cerebellum, amygdala, and striatum (Freedland et al. 2002; Iversen 2003; Pontieri et al. 1999; Quickfall and Crockford 2006). Human studies examining CNS sequelae of chronic marijuana use provide evidence for increased metabolism (Block et al. 2000; Mathew et al. 2002) and activation of alternate neural pathways within these regions (Eldreth et al. 2004; Kanayama et al. 2004). Further adverse effects may result from the pharmacological interaction of alcohol and marijuana, where THC has been reported to markedly enhance apoptotic properties of ethanol. In infant rats, administration of THC alone did not result in neurodegeneration; however, the combination of THC and a mildly intoxicating dose of ethanol induced significant apoptotic neuronal cell death, similar to that observed at high doses of ethanol alone (Hansen et al. 2008).

In sum, studies of adolescent alcohol and marijuana use indicate weaknesses in neuropsychological functioning in the areas of attention, speeded information processing, spatial skills, learning and memory, and complex behaviors such as planning and problem solving even after 28 days of sustained abstinence (Brown et al. 2000; Medina et al. 2007a; Tapert and Brown 1999, 2000; Tapert et al. 2002). There are also associated changes in brain structure and function that include altered prefrontal, cerebellar, and hippocampal volumes, reduced white matter microstructural integrity, and atypical brain activation patterns (Bava et al. 2009; Hanson et al. 2010; Jacobsen et al. 2007; Medina et al. 2010; Schweinsburg et al. 2005b, 2008; Tapert et al. 2001b, 2004, 2007). There may be potential reversibility of brain structural changes with long-term abstinence (Delisi et al. 2006), though additional studies are needed to understand the extent to which abnormalities persist or remit with time. Further, the potential interaction of alcohol and marijuana are of concern considering that comorbid use is common (Medina et al. 2007a).

\section{Risk-Taking Behavior and Substance Use}

It is postulated that there is an asynchronous development of reward and control systems that enhance adolescents' responsivity to incentives and risky behaviors (Casey et al. 2008;
Ernst et al. 2006; Somerville et al. 2010; Steinberg et al. 2008). Bottom-up limbic systems involved in emotional and incentive processing purportedly develop earlier than topdown prefrontal systems involved in behavioral control. In situations with high emotional salience, the more mature limbic regions will override prefrontal regions, resulting in poor decisions. The developmental imbalance is unique to adolescents, as children have equally immature limbic and prefrontal regions, while adults benefit from fully developed systems. Within this model, risky behaviors of adolescents is understood in light of limbic system driven choices to seek immediate gratification rather than long-term gains. Moreover, this relationship may be more pronounced in adolescents with increased emotional reactivity.

Behavioral and fMRI studies show increased subcortical activation when making risky choices and less activation of prefrontal cortex, as well as immature connectivity between emotion processing and control systems overall (Hare et al. 2008). A more specific characterization of these patterns using comparisons of low- and high-risk gambles indicated that high-risk choices activate reward-related ventral striatum and medial prefrontal cortex, whereas low-risk choices activate control-related dorsolateral prefrontal cortex. Interestingly, activation of the ventral medial prefrontal cortex was positively associated with risk-taking propensity, whereas activation of the dorsal medial prefrontal cortex was negatively associated with risk-taking propensity (Van Leijenhorst et al. 2010), suggesting that distinct neural profiles may contribute to the inhibition or facilitation of risky behaviors.

\section{Other Influences on Substance Use Tendencies}

Several factors are associated with an increased risk of initiating heavy drinking during adolescence. Among these, a positive family history of alcohol dependence is perhaps the most robust indicator of risk for an alcohol use disorder (Cloninger et al. 1986; Goodwin 1979; Schuckit 1985). Offspring of alcoholics are 3-5 times more likely to develop AUD than offspring of non-alcoholics (Cotton 1979; Finn et al. 1990; Goodwin 1985; Lieb et al. 2002; Merikangas et al. 1998; Schuckit et al. 1972) with a particularly high level of risk for dense (Dawson and Grant 1998) or multigenerational (Hill et al. 2000; Peterson et al. 1992) family history. Externalizing disorders including conduct disorder, oppositional defiant disorder, and ADHD, and related conditions, such as juvenile delinquency, behavioral undercontrol, aggression, impulsivity, high novelty seeking (Sher et al. 2000; Zuckerman and Kuhlman 2000), and sensation-seeking personalities (Martin et al. 2004) are associated with increased risk for substance use disorders (Bukstein et al. 1989; Chassin et al. 1999; DeMilio 1989; Kaminer and Frances 1991; Rose et al. 2004; Schuckit 1998; Wilens et al. 1997). Conduct disorder 
that is comorbid with ADHD poses a high risk for substance use disorders, although the risk is halved for treated youth (Wilens et al. 2003). Early onset substance use (i.e., at or before age 14) is associated with an increased likelihood of developing dependence (Grant 1998; Grant et al. 2001). Youth with a positive family history of substance use who start drinking in early adolescence are at exceptionally elevated risk for a substance use disorder (Grant 1998; Warner and White 2003).

\section{Concluding Remarks}

The adolescent brain undergoes dynamic change in neurochemistry, fiber architecture, and overall tissue composition. The course of these maturational processes is being charted with greater specificity owing to advanced in vivo neuroimaging. These techniques indicate grey matter volume reductions and protracted development of white matter in projection and association fibers known to support complex cognitive and behavioral skills. Enhancement of frontosubcortical circuitry is notable during adolescence, though asynchronous maturation of prefrontal and limbic systems may render youth more vulnerable to risk taking, particularly in incentivized situations. This is manifest in concerning prevalence rates of substance use among adolescents. Bingepattern alcohol consumption and comorbid marijuana use are common and associated with identifiable neural consequences. Deficits in attention, memory, and executive functioning are apparent in adolescent substance users, and are associated with alterations in prefrontal, hippocampal, and cerebellar structure and function as well as poor white matter integrity. Understanding risk and protective factors for alcohol and marijuana use in adolescents and the consequences of sustained use are the subject of ongoing study and programming efforts. The frequency of polysubstance use underscores the need for research examining the interactive effects of substances on brain structure, particularly given that the pharmacodynamics of one drug may mitigate or potentiate the neurotoxic components of another. Further, integration of genetic, hormonal, neural, and behavioral characteristics via cross-modal analyses is needed in future research to identify biomarkers for substance problems and targets for treatment. In addition, longitudinal neurobehavioral studies will be important for assessing and differentiating the enduring and potentially reversible effects of alcohol and other drug use during adolescence.

Acknowledgements This work was supported through grants from the National Institutes of Health (R01 AA13419, R01 DA021182, and P20 DA024194-0002). We gratefully acknowledge Rachel Thayer for technical assistance.

Open Access This article is distributed under the terms of the Creative Commons Attribution Noncommercial License which per- mits any noncommercial use, distribution, and reproduction in any medium, provided the original author(s) and source are credited.

\section{References}

Aarts, E., Roelofs, A., Franke, B., Rijpkema, M., Fernandez, G., Helmich, R. C., et al. (2010). Striatal dopamine mediates the interface between motivational and cognitive control in humans: evidence from genetic imaging. Neuropsychopharmacology, 35(9), 1943-1951.

Abdullaev Y., Posner M. I., Nunnally R., \& Dishion T. J. (2010) Functional MRI evidence for inefficient attentional control in adolescent chronic cannabis abuse. Behavioural Brain Research, 215(1), 45-57.

Akil, M., \& Lewis, D. A. (1992). Postnatal development of parvalbumin immunoreactivity in axon terminals of basket and chandelier neurons in monkey neocortex. Progress in Neuropsychopharmacology and Biological Psychiatry, 16(3), 329-337.

Andersen, S. L., Rutstein, M., Benzo, J. M., Hostetter, J. C., \& Teicher, M. H. (1997). Sex differences in dopamine receptor overproduction and elimination. Neuroreport, 8(6), 1495-1498.

Anderson, V. A., Anderson, P., Northam, E., Jacobs, R., \& Catroppa, C. (2001). Development of executive functions through late childhood and adolescence in an Australian sample. Developmental Neuropsychology, 20(1), 385-406.

Asato, M. R., Terwilliger, R., Woo, J., \& Luna, B. (2010). White Matter Development in Adolescence: A DTI Study. Cerebral Cortex.

Ashtari, M., Cervellione, K. L., Hasan, K. M., Wu, J., McIlree, C., Kester, H., et al. (2007). White matter development during late adolescence in healthy males: a cross-sectional diffusion tensor imaging study. Neuroimage, 35(2), 501-510.

Barnea-Goraly, N., Menon, V., Eckert, M., Tamm, L., Bammer, R., Karchemskiy, A., et al. (2005). White matter development during childhood and adolescence: a cross-sectional diffusion tensor imaging study. Cerebral Cortex, 15(12), 1848-1854.

Bava, S., Frank, L. R., McQueeny, T., Schweinsburg, B. C., Schweinsburg, A. D., \& Tapert, S. F. (2009). Altered white matter microstructure in adolescent substance users. Psychiatry Research, 173(3), 228-237.

Bava, S., Jacobus, J., Mahmood, O., Yang, T. T., \& Tapert, S. F. (2010). Neurocognitive correlates of white matter quality in adolescent substance users. Brain and Cognition, 72(3), 347-354.

Bava, S., Thayer, R., Jacobus, J., Ward, M., Jernigan, T. L., \& Tapert, S. F. (2010). Longitudinal characterization of white matter maturation during adolescence. Brain Research, 1327, 38-46.

Beaulieu, C., Plewes, C., Paulson, L. A., Roy, D., Snook, L., Concha, L., et al. (2005). Imaging brain connectivity in children with diverse reading ability. Neuroimage, 25(4), 1266-1271.

Behrens, M. M., \& Sejnowski, T. J. (2009). Does schizophrenia arise from oxidative dysregulation of parvalbumin-interneurons in the developing cortex? Neuropharmacology, 57(3), 193-200.

Benes, F. M. (1989). Myelination of cortical-hippocampal relays during late adolescence. Schizophr Bull, 15(4), 585-593.

Blanton, R. E., Levitt, J. G., Peterson, J. R., Fadale, D., Sporty, M. L., Lee, M., et al. (2004). Gender differences in the left inferior frontal gyrus in normal children. Neuroimage, 22(2), 626-636.

Block, R. I., O’Leary, D. S., Hichwa, R. D., Augustinack, J. C., Ponto, L. L., Ghoneim, M. M., et al. (2000). Cerebellar hypoactivity in frequent marijuana users. Neuroreport, 11(4), 749-753.

Bonekamp, D., Nagae, L. M., Degaonkar, M., Matson, M., Abdalla, W. M., Barker, P. B., et al. (2007). Diffusion tensor imaging in children and adolescents: reproducibility, hemispheric, and agerelated differences. Neuroimage, 34(2), 733-742. 
Bourgeois, J. P., Goldman-Rakic, P. S., \& Rakic, P. (1994). Synaptogenesis in the prefrontal cortex of rhesus monkeys. Cerebral Cortex, 4(1), 78-96.

Brown, S. A., Tapert, S. F., Granholm, E., \& Delis, D. C. (2000). Neurocognitive functioning of adolescents: effects of protracted alcohol use. Alcoholism: Clinical and Experimental Research, 24 (2), 164-171.

Brown, S. A., McGue, M., Maggs, J., Schulenberg, J., Hingson, R., Swartzwelder, S., et al. (2008). A developmental perspective on alcohol and youths 16 to 20 years of age. Pediatrics, 121(Suppl 4), S290-S310.

Bukstein, O., Brent, D., \& Kaminer, Y. (1989). Comorbidity of substance abuse and other psychiatric disorders in adolescents. Am J Psychiatry, 146, 1131-1141.

Caldwell, L. C., Schweinsburg, A. D., Nagel, B. J., Barlett, V. C., Brown, S. A., \& Tapert, S. F. (2005). Gender and adolescent alcohol use disorders on BOLD (blood oxygen level dependent) response to spatial working memory. Alcohol \& Alcoholism, 40, 194-200.

Casey, B. J., Jones, R. M., \& Hare, T. A. (2008). The adolescent brain. Annals of the New York Academy of Sciences, 1124(111126).

Caviness, V. S., Jr., Kennedy, D. N., Richelme, C., Rademacher, J., \& Filipek, P. A. (1996). The human brain age 7-11 years: a volumetric analysis based on magnetic resonance images. Cerebral Cortex, 6(5), 726-736.

Chassin, L., Pitts, S. C., DeLucia, C., \& Todd, M. (1999). A longitudinal study of children of alcoholics: predicting young adult substance use disorders, anxiety, and depression. Journal of Abnormal Psychology, 108(1), 106-119.

Choudhury, S., Blakemore, S. J., \& Charman, T. (2006). Social cognitive development during adolescence. Social Cognitive and Affective Neuroscience, 1(3), 165-174.

Cloninger, C. R., Sigvardsson, S., Reich, T., \& Bohman, M. (1986). Inheritance of risk to develop alcoholism. National Institute of Drug Abuse Research Monograph Series, 66, 86-96.

Conklin, H. M., Luciana, M., Hooper, C. J., \& Yarger, R. S. (2007). Working memory performance in typically developing children and adolescents: behavioral evidence of protracted frontal lobe development. Developmental Neuropsychology, 31(1), 103128 .

Conturo, T. E., Lori, N. F., Cull, T. S., Akbudak, E., Snyder, A. Z., Shimony, J. S., et al. (1999). Tracking neuronal fiber pathways in the living human brain. Proceedings of the National Academy of Sciences USA, 96(18), 10422-10427.

Cotton, N. S. (1979). The familial incidence of alcoholism: A review. Journal of Studies on Alcohol, 40, 89-116.

Crews, F. T., Buckley, T., Dodd, P. R., Ende, G., Foley, N., Harper, C., et al. (2005). Alcoholic neurobiology: changes in dependence and recovery. Alcoholism: Clinical and Experimental Research, 29(8), 1504-1513

Cruz, D. A., Eggan, S. M., \& Lewis, D. A. (2003). Postnatal development of pre- and postsynaptic GABA markers at chandelier cell connections with pyramidal neurons in monkey prefrontal cortex. Journal of Comparative Neurology, 465(3), 385-400.

Cruz, D. A., Weaver, C. L., Lovallo, E. M., Melchitzky, D. S., \& Lewis, D. A. (2009). Selective alterations in postsynaptic markers of chandelier cell inputs to cortical pyramidal neurons in subjects with schizophrenia. Neuropsychopharmacology, 34 (9), 2112-2124.

Cunningham, M. G., Bhattacharyya, S., \& Benes, F. M. (2002). Amygdalo-cortical sprouting continues into early adulthood: implications for the development of normal and abnormal function during adolescence. Journal of Comparative Neurology, 453(2), 116-130.
Cunningham, M. G., Bhattacharyya, S., \& Benes, F. M. (2008). Increasing Interaction of amygdalar afferents with GABAergic interneurons between birth and adulthood. Cerebral Cortex, 18 (7), 1529-1535.

Dawson, D. A., \& Grant, B. F. (1998). Family history of alcoholism and gender: their combined effects on DSM-IV alcohol dependence and major depression. Journal of Studies on Alcohol, 59, 97-106.

De Bellis, M. D., Clark, D. B., Beers, S. R., Soloff, P. H., Boring, A. M., Hall, J., et al. (2000). Hippocampal volume in adolescentonset alcohol use disorders. American Journal of Psychiatry, 157 (5), 737-744.

De Bellis, M. D., Keshavan, M. S., Beers, S. R., Hall, J., Frustaci, K., Masalehdan, A., et al. (2001). Sex differences in brain maturation during childhood and adolescence. Cerebral Cortex, 11, 552557.

De Bellis, M. D., Narasimhan, A., Thatcher, D. L., Keshavan, M. S., Soloff, P., \& Clark, D. B. (2005). Prefrontal cortex, thalamus, and cerebellar volumes in adolescents and young adults with adolescent-onset alcohol use disorders and comorbid mental disorders. Alcoholism: Clinical and Experimental Research, 29 (9), 1590-1600.

De Bellis, M. D., Van Voorhees, E., Hooper, S. R., Gibler, N., Nelson, L., Hege, S. G., et al. (2008). Diffusion tensor measures of the corpus callosum in adolescents with adolescent onset alcohol use disorders. Alcoholism: Clinical and Experimental Research, 32 (3), 395-404.

Delisi, L. E., Bertisch, H. C., Szulc, K. U., Majcher, M., Brown, K., Bappal, A., et al. (2006). A preliminary DTI study showing no brain structural change associated with adolescent cannabis use. Harm Reduction Journal, 3, 17.

DeMilio, L. (1989). Psychiatric syndromes in adolescent substance abusers. American Journal of Psychiatry, 146, 1212-1214.

Eldreth, D. A., Matochik, J. A., Cadet, J. L., \& Bolla, K. I. (2004). Abnormal brain activity in prefrontal brain regions in abstinent marijuana users. Neuroimage, 23(3), 914-920.

Eluvathingal, T. J., Hasan, K. M., Kramer, L., Fletcher, J. M., \& Ewing-Cobbs, L. (2007). Quantitative diffusion tensor tractography of association and projection fibers in normally developing children and adolescents. Cerebral Cortex, 17 (12), 2760-2768.

Ernst, M., Pine, D. S., \& Hardin, M. (2006). Triadic model of the neurobiology of motivated behavior in adolescence. Psychological Medicine, 36(3), 299-312.

Estruch, R., Nicolas, J. M., Salamero, M., Aragon, C., Sacanella, E., Fernandez-Sola, J., et al. (1997). Atrophy of the corpus callosum in chronic alcoholism. Journal of the Neurological Sciences, 146 (2), 145-151.

Fant, R. V., Heishman, S. J., Bunker, E. B., \& Pickworth, W. B. (1998). Acute and residual effects of marijuana in humans. Pharmacology Biochemistry and Behavior, 60(4), 777-784.

Finn, P., Kleinman, I., \& Pihl, R. (1990). The lifetime prevalence of psychopathology in men with multigenerational family histories of alcoholism. J Nerv Ment Dis, 178, 500-504.

Forbes, E. E., Ryan, N. D., Phillips, M. L., Manuck, S. B., Worthman, C. M., Moyles, D. L., et al. (2010). Healthy adolescents' neural response to reward: associations with puberty, positive affect, and depressive symptoms. Journal of the American Academy of Child and Adolescent Psychiatry, 49(2), 162-172. e161-165.

Freedland, C. S., Whitlow, C. T., Miller, M. D., \& Porrino, L. J. (2002). Dose-dependent effects of Delta9-tetrahydrocannabinol on rates of local cerebral glucose utilization in rat. Synapse, 45 (2), 134-142.

Fryer, S. L., Frank, L. R., Spadoni, A. D., Theilmann, R. J., Nagel, B. J., Schweinsburg, A. D., et al. (2008). Microstructural integrity of 
the corpus callosum linked with neuropsychological performance in adolescents. Brain and Cognition, 67(2), 225-233.

Galvan, A. (2010). Adolescent development of the reward system. Frontiers in Human Neuroscience, 4, 6.

Galvan A., Hare T. A., Parra C. E., Penn J., Voss H., Glover G., \& Casey B. J. (2006). Earlier development of the accumbens relative to orbitofrontal cortex might underlie risk-taking behavior in adolescents. Journal of Neuroscience, 26(25), 6885-92.

Galvan, A., Hare, T., Voss, H., Glover, G., \& Casey, B. J. (2007). Risk-taking and the adolescent brain: who is at risk? Developmental Science, 10(2), F8-F14

Geier, C. F., Terwilliger, R., Teslovich, T., Velanova, K., \& Luna, B. (2010). Immaturities in reward processing and its influence on inhibitory control in adolescence. Cerebral Cortex, 20(7), 16131629.

Giancola, P. R., Mezzich, A. C., \& Tarter, R. E. (1998). Disruptive, delinquent and aggressive behavior in female adolescents with a psychoactive substance use disorder: relation to executive cognitive functioning. Journal on Studies of Alcohol, 59(5), $560-567$.

Giedd, J. N. (2004). Structural magnetic resonance imaging of the adolescent brain. Annals of the New York Academy of Sciences, $1021,77-85$.

Giedd, J. N. (2008). The teen brain: insights from neuroimaging. Journal of Adolescent Health, 42(4), 335-343.

Giedd, J. N., Castellanos, F. X., Rajapakse, J. C., Vaituzis, A. C., \& Rapoport, J. L. (1997). Sexual dimorphism of the developing human brain. Progress in Neuropsychopharmocology and Biological Psychiatry, 21(8), 1185-1201.

Giedd, J. N., Blumenthal, J., Jeffries, N. O., Castellanos, F. X., Liu, H., Zijdenbos, A., et al. (1999). Brain development during childhood and adolescence: a longitudinal MRI study. Nature Neuroscience, 2(10), 861-863.

Giorgio, A., Watkins, K. E., Douaud, G., James, A. C., James, S., De Stefano, N., et al. (2008). Changes in white matter microstructure during adolescence. Neuroimage, 39(1), 52-61.

Giorgio, A., Watkins, K. E., Chadwick, M., James, S., Winmill, L., Douaud, G., et al. (2010). Longitudinal changes in grey and white matter during adolescence. Neuroimage, 49(1), 94 103.

Gogtay, N., Giedd, J. N., Lusk, L., Hayashi, K. M., Greenstein, D., Vaituzis, A. C., et al. (2004). Dynamic mapping of human cortical development during childhood through early adulthood. Proceedings of the National Academy of Sciences USA, 101(21), 8174-8179.

Goodwin, D. W. (1979). Alcoholism and heredity: a review and hypothesis. Archives of General Psychiatry, 36, 57-61.

Goodwin, D. (1985). Alcoholism and genetics: the sins of the fathers. Archives of General Psychiatry, 42, 171-174.

Grant, B. F. (1998). The impact of a family history of alcoholism on the relationship between age at onset of alcohol use and DSM-IV alcohol dependence: results from the National Longitudinal Alcohol Epidemiologic Survey. Alcohol Health \& Research World, 22, 144-147.

Grant, B. F., Stinson, F. S., \& Harford, T. C. (2001). Age at onset of alcohol use and DSM IV alcohol abuse and dependence: a 12 year follow up. J Subst Abuse, 13(4), 493-504.

Hansen, H. H., Krutz, B., Sifringer, M., Stefovska, V., Bittigau, P., Pragst, F., et al. (2008). Cannabinoids enhance susceptibility of immature brain to ethanol neurotoxicity. Annals of Neurology, 64 (1), 42-52.

Hanson, K. L., Medina, K. L., Nagel, B. J., Spadoni, A. D., Gorlick, A., \& Tapert, S. F. (2010). Hippocampal volumes in adolescents with and without a family history of alcoholism. American Journal of Drug and Alcohol Abuse, 36(3), 161-167.
Hare, T. A., Tottenham, N., Galvan, A., Voss, H. U., Glover, G. H., \& Casey, B. J. (2008). Biological substrates of emotional reactivity and regulation in adolescence during an emotional go-nogo task. Biological Psychiatry, 63(10), 927-934.

Hill, S. Y., Shen, S., Lowers, L., \& Locke, J. (2000). Factors predicting the onset of adolescent drinking in families at high risk for developing alcoholism. Biological Psychiatry, 48(4), 265275.

Hua, K., Oishi, K., Zhang, J., Wakana, S., Yoshioka, T., Zhang, W., et al. (2009). Mapping of functional areas in the human cortex based on connectivity through association fibers. Cerebral Cortex, 19(8), 1889-1895.

Huttenlocher, P. R. (1979). Synaptic density in human frontal cortexdevelopmental changes and effects of aging. Brain Research, 163 (2), 195-205.

Huttenlocher, P. R. (1990). Morphometric study of human cerebral cortex development. Neuropsychologia, 28, 517-527.

Huttenlocher, P. R., \& Dabholkar, A. S. (1997). Regional differences in synaptogenesis in human cerebral cortex. Journal of Comparative Neurology, 387(2), 167-178.

Iversen, L. (2003). Cannabis and the brain. Brain, 126(Pt 6), 12521270.

Jacobsen, L. K., Pugh, K. R., Constable, R. T., Westerveld, M., \& Mencl, W. E. (2007). Functional correlates of verbal memory deficits emerging during nicotine withdrawal in abstinent adolescent cannabis users. Biological Psychiatry, 61(1), 31-40.

Jacobus, J., McQueeny, T., Bava, S., Schweinsburg, B. C., Frank, L. R., Yang, T. T., et al. (2009). White matter integrity in adolescents with histories of marijuana use and binge drinking. Neurotoxicology and Teratology, 31(6), 349-355.

Jernigan, T. L., \& Tallal, P. (1990). Late childhood changes in brain morphology observable with MRI. Dev Med Child Neurol, 32(5), 379-385.

Jernigan, T. L., Trauner, D. A., Hesselink, J. R., \& Tallal, P. A. (1991). Maturation of human cerebrum observed in vivo during adolescence. Brain, 114(Pt 5), 2037-2049.

Johns, A. (2001). Psychiatric effects of cannabis. British Journal of Psychiatry, 178, 116-122.

Johnston, L. D., O’Malley, P. M., Bachman, J. G., \& Schulenberg, J. E. (2009). Monitoring the future national results on adolescent drug use: Overview of key findings, 2008. Bethesda: National Institute on Drug Abuse.

Jucaite, A., Forssberg, H., Karlsson, P., Halldin, C., \& Farde, L. (2010). Age-related reduction in dopamine D1 receptors in the human brain: from late childhood to adulthood, a positron emission tomography study. Neuroscience, 167(1), 104-110.

Kaminer, Y., \& Frances, R. (1991). Inpatient treatment of adolescents with psychiatric and substance abuse disorders. Hospital and Community Psychiatry, 42, 894-896.

Kanayama, G., Rogowska, J., Pope, H. G., Gruber, S. A., \& YurgelunTodd, D. A. (2004). Spatial working memory in heavy cannabis users: a functional magnetic resonance imaging study. Psychopharmacology (Berl), 176(3-4), 239-247.

Koepp, M. J., Gunn, R. N., Lawrence, A. D., Cunningham, V. J., Dagher, A., Jones, T., et al. (1998). Evidence for striatal dopamine release during a video game. Nature, 393(6682), 266-268.

Lambe, E. K., Krimer, L. S., \& Goldman-Rakic, P. S. (2000). Differential postnatal development of catecholamine and serotonin inputs to identified neurons in prefrontal cortex of rhesus monkey. Journal of Neuroscience, 20(23), 8780-8787.

Lane, S. D., Cherek, D. R., Tcheremissine, O. V., Steinberg, J. L., \& Sharon, J. L. (2007). Response perseveration and adaptation in heavy marijuana-smoking adolescents. Addictive Behaviors, 32 (5), 977-990. 
Lebel, C., \& Beaulieu, C. (2009). Lateralization of the arcuate fasciculus from childhood to adulthood and its relation to cognitive abilities in children. Human Brain Mapping, 30(11), 3563-3573.

Lebel, C., Walker, L., Leemans, A., Phillips, L., \& Beaulieu, C. (2008). Microstructural maturation of the human brain from childhood to adulthood. Neuroimage, 40(3), 1044-1055.

Lenroot, R. K., \& Giedd, J. N. (2006). Brain development in children and adolescents: insights from anatomical magnetic resonance imaging. Neuroscience and Biobehavioral Reviews, 30(6), 718729.

Lenroot, R. K., Gogtay, N., Greenstein, D. K., Wells, E. M., Wallace, G. L., Clasen, L. S., et al. (2007). Sexual dimorphism of brain developmental trajectories during childhood and adolescence. Neuroimage, 36(4), 1065-1073.

Lewis, D. A. (1997). Schizophrenia and disordered neural circuitry. Schizophrenia Bulletin, 23(3), 529-531.

Lieb, R., Merikangas, K. R., Hofler, M., Pfister, H., Isensee, B., \& Wittchen, H. U. (2002). Parental alcohol use disorders and alcohol use and disorders in offspring: a community study. Psychol Med, 32(1), 63-78.

Mabbott, D. J., Rovet, J., Noseworthy, M. D., Smith, M. L., \& Rockel, C. (2009). The relations between white matter and declarative memory in older children and adolescents. Brain Research, 1294, 80-90.

Macleod, J., Oakes, R., Copello, A., Crome, I., Egger, M., Hickman, M., et al. (2004). Psychological and social sequelae of cannabis and other illicit drug use by young people: a systematic review of longitudinal, general population studies. Lancet, 363(9421), $1579-1588$.

Martin, C. A., Kelly, T. H., Rayens, M. K., Brogli, B., Himelreich, K., Brenzel, A., et al. (2004). Sensation seeking and symptoms of disruptive disorder: association with nicotine, alcohol, and marijuana use in early and mid-adolescence. Psychol Rep, 94(3 Pt 1), 1075-1082.

Mathew, R. J., Wilson, W. H., Turkington, T. G., Hawk, T. C., Coleman, R. E., DeGrado, T. R., et al. (2002). Time course of tetrahydrocannabinol-induced changes in regional cerebral blood flow measured with positron emission tomography. Psychiatry Research, 116(3), 173-185.

McQueeny, T., Schweinsburg, B. C., Schweinsburg, A. D., Jacobus, J., Bava, S., Frank, L. R., et al. (2009). Altered White Matter Integrity in Adolescent Binge Drinkers. Alcoholism: Clinical and Experimental Research.

Medina, K. L., Hanson, K. L., Schweinsburg, A. D., Cohen-Zion, M., Nagel, B. J., \& Tapert, S. F. (2007). Neuropsychological functioning in adolescent marijuana users: subtle deficits detectable after a month of abstinence. Journal of the International Neuropsychological Society, 13(5), 807-820.

Medina, K. L., Nagel, B. J., Park, A., McQueeny, T., \& Tapert, S. F. (2007). Depressive symptoms in adolescents: associations with white matter volume and marijuana use. Journal of Child Psychology and Psychiatry, 48(6), 592-600.

Medina, K. L., McQueeny, T., Nagel, B. J., Hanson, K. L., Schweinsburg, A. D., \& Tapert, S. F. (2008). Prefrontal cortex volumes in adolescents with alcohol use disorders: unique gender effects. Alcoholism: Clinical and Experimental Research, 32(3), 386-394.

Medina, K. L., McQueeny, T., Nagel, B. J., Hanson, K. L., Yang, T. T., \& Tapert, S. F. (2009). Prefrontal cortex morphometry in abstinent adolescent marijuana users: subtle gender effects. Addiction Biology, 14(4), 457-468.

Medina, K. L., Nagel, B. J., \& Tapert, S. F. (2010). Abnormal cerebellar morphometry in abstinent adolescent marijuana users. Psychiatry Research, 182(2), 152-159.
Merikangas, K. R., Stolar, M., Stevens, D. E., Goulet, J., Preisig, M. A., Fenton, B., et al. (1998). Familial transmission of substance use disorders. Archives of General Psychiatry, 55, 973-979.

Meyerhoff, D. J., Blumenfeld, R., Truran, D., Lindgren, J., Flenniken, D., Cardenas, V., et al. (2004). Effects of heavy drinking, binge drinking, and family history of alcoholism on regional brain metabolites. Alcoholism: Clinical and Experimental Research, 28(4), 650-661.

Monk, C. S., McClure, E. B., Nelson, E. E., Zarahn, E., Bilder, R. M., Leibenluft, E., et al. (2003). Adolescent immaturity in attention-related brain engagement to emotional facial expressions. Neuroimage, 20(1), 420-428.

Moss, H. B., Kirisci, L., Gordon, H. W., \& Tarter, R. E. (1994). A neuropsychologic profile of adolescent alcoholics. Alcoholism: Clinical and Experimental Research, 18(1), 159-163.

Mukherjee, P., Miller, J. H., Shimony, J. S., Conturo, T. E., Lee, B. C., Almli, C. R., et al. (2001). Normal brain maturation during childhood: developmental trends characterized with diffusiontensor MR imaging. Radiology, 221(2), 349-358.

Nagel, B. J., Schweinsburg, A. D., Phan, V., \& Tapert, S. F. (2005). Reduced hippocampal volume among adolescents with alcohol use disorders without psychiatric comorbidity. Psychiatry Research, 139(3), 181-190.

Nagel, B. J., Medina, K. L., Yoshii, J., Schweinsburg, A. D., Moadab, I., \& Tapert, S. F. (2006). Age-related changes in prefrontal white matter volume across adolescence. Neuroreport, 17(13), 1427-1431.

Nagy, Z., Westerberg, H., \& Klingberg, T. (2004). Maturation of white matter is associated with the development of cognitive functions during childhood. Journal of Cognitive Neuroscience, 16(7), 1227-1233.

Nation, M., \& Heflinger, C. A. (2006). Risk factors for serious alcohol and drug use: the role of psychosocial variables in predicting the frequency of substance use among adolescents. American Journal of Drug and Alcohol Abuse, 32(3), 415-433.

Neal, D. J., \& Fromme, K. (2007). Event-level covariation of alcohol intoxication and behavioral risks during the first year of college. J Consult Clin Psychol, 75(2), 294-306.

Nicolas, J. M., Fernandez-Sola, J., Robert, J., Antunez, E., Cofan, M., Cardenal, C., et al. (2000). High ethanol intake and malnutrition in alcoholic cerebellar shrinkage. Quarterly Journal of Medicine, 93(7), 449-456.

Niogi, S. N., \& McCandliss, B. D. (2006). Left lateralized white matter microstructure accounts for individual differences in reading ability and disability. Neuropsychologia, 44(11), 2178-2188.

Olesen, P. J., Nagy, Z., Westerberg, H., \& Klingberg, T. (2003). Combined analysis of DTI and fMRI data reveals a joint maturation of white and grey matter in a fronto-parietal network. Brain Research: Cognitive Brain Research, 18(1), 48-57.

Paus, T., Zijdenbos, A., Worsley, K., Collins, D. L., Blumenthal, J., Giedd, J. N., et al. (1999). Structural maturation of neural pathways in children and adolescents: in vivo study. Science, 283 (5409), 1908-1911.

Paus, T., Keshavan, M., \& Giedd, J. N. (2008). Why do many psychiatric disorders emerge during adolescence? Nature Reviews Neuroscience, 9(12), 947-957.

Peper, J. S., Brouwer, R. M., Schnack, H. G., van Baal, G. C., van Leeuwen, M., van den Berg, S. M., et al. (2008). Cerebral white matter in early puberty is associated with luteinizing hormone concentrations. Psychoneuroendocrinology, 33(7), 909-915.

Perrin, J. S., Herve, P. Y., Leonard, G., Perron, M., Pike, G. B., Pitiot, A., et al. (2008). Growth of white matter in the adolescent brain: role of testosterone and androgen receptor. Journal of Neuroscience, 28(38), 9519-9524.

Perrin, J. S., Leonard, G., Perron, M., Pike, G. B., Pitiot, A., Richer, L., et al. (2009). Sex differences in the growth of white matter during adolescence. Neuroimage, 45(4), 1055-1066. 
Peterson, J., Finn, P., \& Pihl, R. (1992). Cognitive dysfunction and the inherited predisposition to alcoholism. Journal on Studies of Alcohol, 53, 154-160.

Pfefferbaum, A., \& Sullivan, E. V. (2005). Disruption of brain white matter microstructure by excessive intracellular and extracellular fluid in alcoholism: evidence from diffusion tensor imaging. Neuropsychopharmacology, 30(2), 423-432.

Pfefferbaum, A., Mathalon, D. H., Sullivan, E. V., Rawles, J. M., Zipursky, R. B., \& Lim, K. O. (1994). A quantitative magnetic resonance imaging study of changes in brain morphology from infancy to late adulthood. Archives of Neurology, 51(9), 874-887.

Pfefferbaum, A., Adalsteinsson, E., \& Sullivan, E. V. (2006a). Dysmorphology and microstructural degradation of the corpus callosum: Interaction of age and alcoholism. Neurobiology of Aging, 27(7), 994-1009.

Pfefferbaum, A., Adalsteinsson, E., \& Sullivan, E. V. (2006b). Supratentorial profile of white matter microstructural integrity in recovering alcoholic men and women. Biological Psychiatry, 59(4), 364-372.

Pierpaoli, C., \& Basser, P. J. (1996). Toward a quantitative assessment of diffusion anisotropy. Magnetic Resonance in Medicine, 36(6), 893-906.

Pontieri, F. E., Conti, G., Zocchi, A., Fieschi, C., \& Orzi, F. (1999). Metabolic mapping of the effects of WIN 55212-2 intravenous administration in the rat. Neuropsychopharmacology, 21(6), 773776.

Qiu, D., Tan, L. H., Zhou, K., \& Khong, P. L. (2008). Diffusion tensor imaging of normal white matter maturation from late childhood to young adulthood: voxel-wise evaluation of mean diffusivity, fractional anisotropy, radial and axial diffusivities, and correlation with reading development. Neuroimage, 41(2), 223-232.

Quickfall, J., \& Crockford, D. (2006). Brain neuroimaging in cannabis use: a review. The Journal of Neuropsychiatry and Clinical Neurosciences, 18(3), 318-332.

Rao, S. G., Williams, G. V., \& Goldman-Rakic, P. S. (2000). Destruction and creation of spatial tuning by disinhibition: GABA(A) blockade of prefrontal cortical neurons engaged by working memory. Journal of Neuroscience, 20(1), 485-494.

Reiss, A. L., Abrams, M. T., Singer, H. S., Ross, J. L., \& Denckla, M. B. (1996). Brain development, gender and IQ in children: a volumetric imaging study. Brain, 119, 1763-1774.

Roberts, T. P., \& Schwartz, E. S. (2007). Principles and implementation of diffusion-weighted and diffusion tensor imaging. Pediatric Radiology, 37(8), 739-748.

Rose, R. J., Dick, D. M., Viken, R. J., Pulkkinen, L., \& Kaprio, J. (2004). Genetic and environmental effects on conduct disorder and alcohol dependence symptoms and their covariation at age 14. Alcohol Clin Exp Res, 28(10), 1541-1548.

Rosenberg, D. R., \& Lewis, D. A. (1994). Changes in the dopaminergic innervation of monkey prefrontal cortex during late postnatal development: a tyrosine hydroxylase immunohistochemical study. Biological Psychiatry, 36(4), 272-277.

Royall, D. R., Lauterbach, E. C., Cummings, J. L., Reeve, A., Rummans, T. A., Kaufer, D. I., et al. (2002). Executive control function: a review of its promise and challenges for clinical research. A report from the Committee on Research of the American Neuropsychiatric Association. Journal of Neuropsychiatry and Clinical Neurosciences, 14(4), 377-405.

Rubia, K., Smith, A. B., Brammer, M. J., \& Taylor, E. (2003). Right inferior prefrontal cortex mediates response inhibition while mesial prefrontal cortex is responsible for error detection. Neuroimage, 20(1), 351-358.

SAMSHA. (2009). Results from the 2008 national survey on drug use and health: national findings. Rockville: Office of Applied Studies, DHHS.
Schmithorst, V. J., Wilke, M., Dardzinski, B. J., \& Holland, S. K. (2002). Correlation of white matter diffusivity and anisotropy with age during childhood and adolescence: a cross-sectional diffusion-tensor MR imaging study. Radiology, 222(1), 212 218.

Schmithorst, V. J., Wilke, M., Dardzinski, B. J., \& Holland, S. K. (2005). Cognitive functions correlate with white matter architecture in a normal pediatric population: a diffusion tensor MRI study. Human Brain Mapping, 26(2), 139-147.

Schmithorst, V. J., Holland, S. K., \& Dardzinski, B. J. (2008). Developmental differences in white matter architecture between boys and girls. Hum Brain Mapp, 29(6), 696-710.

Schneiderman, J. S., Buchsbaum, M. S., Haznedar, M. M., Hazlett, E. A., Brickman, A. M., Shihabuddin, L., et al. (2007). Diffusion tensor anisotropy in adolescents and adults. Neuropsychobiology, $55(2), 96-111$

Schuckit, M. A. (1985). The clinical implications of primary diagnostic groups among alcoholics. Archives of General Psychiatry, 42, 1043-1049.

Schuckit, M. A. (1998). Penny-wise, ton-foolish? The recent movement to abolish inpatient alcohol and drug treatment Journal of Studies on Alcohol, 59(1), 5-7.

Schuckit, M. A., Goodwin, D. A., \& Winokur, G. (1972). A study of alcoholism in half siblings. Am J Psychiatry, 128(9), 1132-1136.

Schweinsburg, B. C., Alhassoon, O. M., Taylor, M. J., Gonzalez, R., Videen, J. S., Brown, G. G., et al. (2003). Effects of alcoholism and gender on brain metabolism. American Journal of Psychiatry, 160 (6), 1180-1183.

Schweinsburg, A. D., Nagel, B. J., \& Tapert, S. F. (2005). fMRI reveals alteration of spatial working memory networks across adolescence. Journal of the International Neuropsychological Society, 11(5), 631-644.

Schweinsburg, A. D., Schweinsburg, B. C., Cheung, E. H., Brown, G. G., Brown, S. A., \& Tapert, S. F. (2005). fMRI response to spatial working memory in adolescents with comorbid marijuana and alcohol use disorders. Drug and Alcohol Dependence, 79(2), 201-210.

Schweinsburg, A. D., Nagel, B. J., Schweinsburg, B. C., Park, A., Theilmann, R. J., \& Tapert, S. F. (2008). Abstinent adolescent marijuana users show altered fMRI response during spatial working memory. Psychiatry Research: Neuroimaging.

Schweinsburg, A. D., McQueeny, T., Nagel, B. J., Eyler, L. T., \& Tapert, S. F. (2010). A preliminary study of functional magnetic resonance imaging response during verbal encoding among adolescent binge drinkers. Alcohol, 44(1), 111-117.

Schweinsburg, A. D., Schweinsburg, B. C., Medina, K. L., McQueeny, T., Brown, S. A., \& Tapert, S. F. (2010b). The influence of recency of use on fMRI response during spatial working memory in adolescent marijuana users. Journal of Psychoactive Drugs.

Shaw, P., Kabani, N. J., Lerch, J. P., Eckstrand, K., Lenroot, R., Gogtay, N., et al. (2008). Neurodevelopmental trajectories of the human cerebral cortex. Journal of Neuroscience, 28(14), 35863594.

Sher, K. J., Bartholow, B. D., \& Wood, M. D. (2000). Personality and substance use disorders: A prospective study. Journal of Consulting \& Clinical Psychology, 68(5), 818-829.

Shimony, J. S., McKinstry, R. C., Akbudak, E., Aronovitz, J. A., Snyder, A. Z., Lori, N. F., et al. (1999). Quantitative diffusiontensor anisotropy brain MR imaging: normative human data and anatomic analysis. Radiology, 212(3), 770-784.

Shoal, G. D., Gudonis, L. C., Giancola, P. R., \& Tarter, R. E. (2007). Delinquency as a mediator of the relation between negative affectivity and adolescent alcohol use disorder. Addictive Behaviors, 32(12), 2747-2765. 
Silveri, M. M., Rohan, M. L., Pimentel, P. J., Gruber, S. A., Rosso, I. M., \& Yurgelun-Todd, D. A. (2006). Sex differences in the relationship between white matter microstructure and impulsivity in adolescents. Magn Reson Imaging, 24(7), 833-841.

Snook, L., Paulson, L. A., Roy, D., Phillips, L., \& Beaulieu, C. (2005). Diffusion tensor imaging of neurodevelopment in children and young adults. Neuroimage, 26(4), 1164-1173.

Solowij, N., Stephens, R. S., Roffman, R. A., Babor, T., Kadden, R., Miller, M., et al. (2002). Cognitive functioning of long-term heavy cannabis users seeking treatment. Journal of the American Medical Association, 287(9), 1123-1131.

Somerville, L. H., Jones, R. M., \& Casey, B. J. (2010). A time of change: behavioral and neural correlates of adolescent sensitivity to appetitive and aversive environmental cues. Brain and Cognition, 72(1), 124-133.

Sowell, E. R., Thompson, P. M., Holmes, C. J., Jernigan, T. L., \& Toga, A. W. (1999). In vivo evidence for post-adolescent brain maturation in frontal and striatal regions. Nature Neuroscience, 2 (10), 859-861.

Sowell E. R., Thompson P. M., Tessner K. D., \& Toga A. W. (2001). Mapping continued brain growth and gray matter density reduction in dorsal frontal cortex: Inverse relationships during postadolescent brain maturation. Journal of Neuroscience, 21 (22), 8819-29.

Sowell, E. R., Thompson, P. M., Mattson, S. N., Tessner, K. D., Jernigan, T. L., Riley, E. P., et al. (2002). Regional brain shape abnormalities persist into adolescence after heavy prenatal alcohol exposure. Cerebral Cortex, 12(8), 856-865.

Sowell, E. R., Trauner, D. A., Gamst, A., \& Jernigan, T. L. (2002). Development of cortical and subcortical brain structures in childhood and adolescence: a structural MRI study. Dev Med Child Neurol, 44(1), 4-16.

Sowell, E. R., Peterson, B. S., Thompson, P. M., Welcome, S. E., Henkenius, A. L., \& Toga, A. W. (2003). Mapping cortical change across the human life span. Nature Neuroscience, 6, 309315 .

Spear, L. P. (2000). The adolescent brain and age-related behavioral manifestations. Neuroscience and Biobehavioral Reviews, 24(4), 417-463.

Spear, L. P. (2009). Heightened stress responsivity and emotional reactivity during pubertal maturation: Implications for psychopathology. Dev Psychopathol, 21(1), 87-97.

Spear, L. P. (2010). The behavioral neuroscience of adolescence. New York: W.W. Norton \& Company.

Squeglia, L. M., Jacobus, J., \& Tapert, S. F. (2009). The influence of substance use on adolescent brain development. Clin EEG Neurosci, 40(1), 31-38.

Steinberg, L., Albert, D., Cauffman, E., Banich, M., Graham, S., \& Woolard, J. (2008). Age differences in sensation seeking and impulsivity as indexed by behavior and self-report: evidence for a dual systems model. Dev Psychol, 44(6), 1764-1778.

Suzuki, Y., Matsuzawa, H., Kwee, I. L., \& Nakada, T. (2003). Absolute eigenvalue diffusion tensor analysis for human brain maturation. NMR Biomed, 16(5), 257-260.

Tamnes, C. K., Ostby, Y., Fjell, A. M., Westlye, L. T., Due-Tonnessen, P., \& Walhovd, K. B. (2009). Brain maturation in adolescence and young adulthood: regional age-related changes in cortical thickness and white matter volume and microstructure. Cerebral Cortex, 20(3), 534-548.

Tapert, S. F., \& Brown, S. A. (1999). Neuropsychological correlates of adolescent substance abuse: four-year outcomes. Journal of the International Neuropsychological Society, 5(6), 481-493.

Tapert, S. F., \& Brown, S. A. (2000). Substance dependence, family history of alcohol dependence and neuropsychological functioning in adolescence. Addiction, 95(7), 1043-1053.
Tapert, S. F., Brown, G., Meloy, M., Dager, A., Cheung, E., \& Brown, S. (2001). fMRI measurement of brain function in alcohol use disordered adolescents. Alcoholism: Clinical and Experimental Research, 25, 80A.

Tapert, S. F., Brown, G. G., Kindermann, S. S., Cheung, E. H., Frank, L. R., \& Brown, S. A. (2001). fMRI measurement of brain dysfunction in alcohol-dependent young women. Alcoholism: Clinical and Experimental Research, 25(2), 236-245.

Tapert, S. F., Granholm, E., Leedy, N. G., \& Brown, S. A. (2002). Substance use and withdrawal: neuropsychological functioning over 8 years in youth. Journal of the International Neuropsychological Society, 8(7), 873-883.

Tapert, S. F., Theilmann, R. J., \& Schweinsburg, A. D. (2003). Reduced fractional anisotropy in the splenium of adolescents with alcohol use disorder. Proceedings of the International Society of Magnetic Resonance Medicine 11, 8217.

Tapert, S. F., Schweinsburg, A. D., Barlett, V. C., Brown, S. A., Frank, L. R., Brown, G. G., et al. (2004). Blood oxygen level dependent response and spatial working memory in adolescents with alcohol use disorders. Alcoholism: Clinical and Experimental Research, 28(10), 1577-1586.

Tapert, S. F., Schweinsburg, A. D., Drummond, S. P., Paulus, M. P., Brown, S. A., Yang, T. T., et al. (2007). Functional MRI of inhibitory processing in abstinent adolescent marijuana users. Psychopharmacology (Berl), 194(2), 173-183.

Tarter, R. E., Mezzich, A. C., Hsieh, Y. C., \& Parks, S. M. (1995). Cognitive capacity in female adolescent substance abusers. Drug and Alcohol Dependence, 39(1), 15-21.

Teicher, M. H., Barber, N. I., Gelbard, H. A., Gallitano, A. L., Campbell, A., Marsh, E., et al. (1993). Developmental differences in acute nigrostriatal and mesocorticolimbic system response to haloperidol. Neuropsychopharmacology, 9(2), 147156.

Tucker, J. S., Ellickson, P. L., Collins, R. L., \& Klein, D. J. (2006a). Are drug experimenters better adjusted than abstainers and users?: a longitudinal study of adolescent marijuana use. Journal of Adolescent Health, 39(4), 488-494.

Tucker, J. S., Ellickson, P. L., Collins, R. L., \& Klein, D. J. (2006b). Does solitary substance use increase adolescents' risk for poor psychosocial and behavioral outcomes? A 9-year longitudinal study comparing solitary and social users. Psychology of Addictive Behaviors, 20(4), 363-372.

Tunbridge, E. M., Weickert, C. S., Kleinman, J. E., Herman, M. M., Chen, J., Kolachana, B. S., et al. (2007). Catechol-omethyltransferase enzyme activity and protein expression in human prefrontal cortex across the postnatal lifespan. Cerebral Cortex, 17(5), 1206-1212.

Uhlhaas, P. J., Roux, F., Singer, W., Haenschel, C., Sireteanu, R., \& Rodriguez, E. (2009). The development of neural synchrony reflects late maturation and restructuring of functional networks in humans. Proceedings of the National Academy of Sciences USA, 106(24), 9866-9871.

Van Leijenhorst, L., Moor, B. G., Op de Macks, Z. A., Rombouts, S. A., Westenberg, P. M., \& Crone, E. A. (2010). Adolescent risky decision-making: neurocognitive development of reward and control regions. Neuroimage, 51(1), 345-355.

Warner, L. A., \& White, H. R. (2003). Longitudinal effects of age at onset and first drinking situations on problem drinking. Substance Use and Misuse, 38(14), 1983-2016.

Weickert, C. S., Webster, M. J., Gondipalli, P., Rothmond, D., Fatula, R. J., Herman, M. M., et al. (2007). Postnatal alterations in dopaminergic markers in the human prefrontal cortex. Neuroscience, 144(3), 1109 1119.

Wilens, T. E., Biederman, J., Abrantes, A. M., \& Spencer, T. J. (1997). Clinical characteristics of psychiatrically referred adolescent 
outpatients with substance use disorder. Journal of the American Academy of Child \& Adolescent Psychiatry, 36, 941-947.

Wilens, T. E., Faraone, S. V., Biederman, J., \& Gunawardene, S. (2003). Does stimulant therapy of attention deficit/hyperactivity disorder beget later substance abuse? A meta analytic review of the literature. Pediatrics, 111(1), 179-185.

Wilke, M., Krageloh-Mann, I., \& Holland, S. K. (2007). Global and local development of gray and white matter volume in normal children and adolescents. Exp Brain Research, 178(3), 296-307.

Wilson W., Mathew R., Turkington T., Hawk T., Coleman R.E., \& Provenzale J. (2000). Brain morphological changes and early marijuana use: a magnetic resonance and positron emission tomography study. Journal of Addictive Disseases 19(1), 1-22.

Woo, T. U., Pucak, M. L., Kye, C. H., Matus, C. V., \& Lewis, D. A. (1997). Peripubertal refinement of the intrinsic and associational circuitry in monkey prefrontal cortex. Neuroscience, 80(4), $1149-1158$.

Yakovlev, P. I., \& Lecours, A. R. (1967). The myelogenetic cycles of regional maturation of the brain. In A. Mikowski (Ed.), Regional development of the brain in early life (pp. 3-70). Oxford: Blackwell Scientific.

Yang, T. T., Menon, V., Reid, A. J., Gotlib, I. H., \& Reiss, A. L. (2003). Amygdalar activation associated with happy facial expressions in adolescents: a 3-T functional MRI study. Journal of the American Academy of Child and Adolescent Psychiatry, 42(8), 979-985.

Yurgelun-Todd, D. A., \& Killgore, W. D. (2006). Fear-related activity in the prefrontal cortex increases with age during adolescence: a preliminary fMRI study. Neurosci Lett, 406(3), 194-199.

Zuckerman, M., \& Kuhlman, D. M. (2000). Personality and risktaking: common biosocial factors. Journal of Personality, 68(6), 999-1029. 